Brit. J. prev. soc. Med. (1976), 30, 26-28

\title{
Anencephalus, spina bifida, twins, and teratoma
}

\author{
S. C. ROGERS \\ General Practitioner, Rugby
}

\begin{abstract}
Rogers, S. C. (1976). British Journal of Preventive and Social Medicine, 30, 26-28. Anencephalus, spina bifida, twins, and teratoma. The twin pairs with spina bifida and or anencephalus collected from the literature by Rogers and Weatherall (1976) form the basis for an argument that the apparent rarity of dizygous twins concordant for these malformations may be due to the breakdown of the interamniotic partition and a subsequent fetus-fetus interaction. It is suggested that this may lead to complete or partial destruction of one twin. When cells survive they may form teratoma or patches of anomalous skin cover. The hypothesis that monozygous twins concordant for these defects may form double monsters is re-stated. The present hypothesis predicts that the incidence of pineal and intraspinal teratoma will vary in time and place with anencephalus and spina bifida, and that the scalp type hairs found over or around spina bifida may prove, in male infants, to have female chromosomes.
\end{abstract}

Rogers (1969) suggested that the apparent rarity of twins concordant for anencephalus or spina bifida might be partially explained by the fusion of such twins to produce double monsters. Knox $(1970,1974)$ further explored this observation in his fetus-fetus interaction hypothesis which postulated that dizygous twins interact on occasions in such a way that one twin disappears while the surviving twin is damaged and later born anencephalic. These hypotheses are modified and developed in this study in the light of a recent collection of twin studies (Rogers and Weatherall, 1976).

\section{HYPOTHESIS}

1. Twins having epithelial defects are liable to adhere to the interamniotic partition in early pregnancy. This is followed by the breakdown of that partition and the production of a secondary mono-amniotic pregnancy.

2. Monozygous twins with epithelial defects are then liable to fuse together with the production of double monsters.

3. Dizygous twins in this situation are liable to fuse together and then undergo a fetusfetus interaction which leads to the complete or partial destruction of one twin.
4. A twin partially destroyed by such interaction may be recognized as a teratoma or as an area of inappropriate skin cover to the defect.

\section{Observations}

Mono-amniotic Twin Pregnancies

Wharton, Edwards, and Cameron (1968) found only 18 pairs of mono-amniotic twins in a series of 581 twin pairs, indicating the rarity of this type of twinning. Pedlow (1961) gave the incidence of severe congenital malformation in his collected series of mono-amniotic twins as $9 \cdot 2 \%$.

Most writers on the subject suggest that the mono-amniotic twin pregnancy causes the con- genital malformation. Here it is postulated that the congenital malformation may be a cause of the mono-amniotic state.

Twin Studies

Rogers and Weatherall (1976) have assembled from the literature a series of 681 twin pairs in which anencephalus or spina bifida have beenc reported, and their results are summarized in the Table.

The findings in the Table suggest that the concordance rate is lower in unlike sex twins. 
TABLE

COLLECTED SERIES OF TWINS KNOWN TO BE CONCORDANT OR DISCORDANT FOR SPINA BIFIDA AND OR ANENCEPHALUS

\begin{tabular}{|c|c|c|c|c|c|c|c|}
\hline \multirow{2}{*}{\multicolumn{3}{|c|}{ Twin Pairs }} & \multicolumn{2}{|c|}{ Discordant } & \multicolumn{2}{|c|}{ Concordant } & \multirow{2}{*}{$\begin{array}{l}\text { Total } \\
\text { (No.) }\end{array}$} \\
\hline & & & No. & $\%$ & No. & $\%$ & \\
\hline Like sex & & .. & 457 & $93 \cdot 6$ & 31 & $6 \cdot 4$ & 488 \\
\hline Unlike sex & .. & .. & 190 & $98 \cdot 4$ & 3 & $1 \cdot 6$ & 193 \\
\hline Total & .. & $\ldots$ & 647 & & 34 & & 681 \\
\hline
\end{tabular}

After Rogers and Weatherall (1975).

Fisher's two-tailed exact test applied to these data show that the probability of this observation arising by chance is $P<0.01$.

It is generally accepted that approximately $70 \%$ of like sex twins are dizygous and there is no reason to suppose that the concordance rate in dizygous twins differs between like sex pairs and unlike sex pairs. If we assume that the like sex pairs in this collected series included 342 dizygous pairs, then these would be expected to give rise to five concordant pairs and the remaining 146 monozygous twin pairs to 26 concordant pairs-that is, a rate of $17 \cdot 8 \%$.

The risk to the siblings of infants with anencephalus or spina bifida is between $4 \%$ and $5 \%$ (Yen and MacMahon, 1968; Carter, David, and Laurence, 1968; Carter and Evans, 1973), and the theoretically expected risk in monozygous twins is between $16 \%$ and $25 \%$. In contrast the observed concordance rate in dizygous twins of $1.6 \%$ is markedly below the theoretically expected rate of $4 \%$ to $5 \%$.

Spontaneous abortion of concordant twins is often put forward as an explanation for their rarity in these series, but it is difficult to see why this should occur only in dizygous twins and why monozygous twins should be spared. The advantages of postulating different forms of fetus-fetus interactions in the different forms of twinning are clear.

\section{DOUble MONSTERS}

The hypothesis that monozygous twins concordant for spina bifida may fuse on rare occasions to form pyopagus twins seems acceptable. The possibility that twins concordant for anencephalus may fuse to form crainiopagus twins seems less unlikely because some early human abortions have been found to suffer from exencephalus rather than anencephalus (Nishimura et al., 1968). The early fusion of such twins may well protect the developing cerebral tissue from the toxic effects of amniotic fluid and enable normal development of the brain to take place. Rickman (1968) has described the protective effect of full thickness intrauterine skin cover on the spinal cord in spina bifida, and a similar effect may be seen in cranium bifida or encephalocele.

The study of Todorov et al. (1974) of 14 examples of crainiopagus emphasizes the low male : female sex ratio $(3: 11)$ that would be expected from their formation in this way.

\section{TERATOMA}

A very wide variety of teratoma have been described and some of these may be relevant to this hypothesis. The extreme situation of fetus in fetu can hardly be explained in any way except by the incorporation of one twin within another, possibly by fusion at the site of an exomphalous. Anencephalus or spina bifida is common in the incorporated twin (Lord, 1956).

Linder and Power (1970), in a study of the isoenzymes of ovarian teratoma and their hosts, showed that where the host was heterogeneous for a pair of isoenzymes the teratoma was homogeneous for that pair in 20 out of 30 pairs studied. They noted that there were no phenotypes present in a tumour that was absent in its host. This loss of gene effect is of the type that would be necessary for the survival of cells derived from a non-identical twin. This and the occurrence of $\mathrm{XX}$ and XO cell lines in teratoma carried by male hosts (Hunter and Lennox, 1954; Myers, 1959; Theiss, Ashby, and Mostofi, 1960; Laurent, Rousseau, and Nezelof, 1968) suggest that after the fusion of dizygous twins concordant for exencephalus or spina bifida a fetus-fetus interaction may take place leading to the complete or partial destruction of one twin. Cells from the twin under attack may undergo somatic mutations with loss of phenotypes, and such mutated cells may be able to survive the attack and persist as teratoma, or as patches of aberrant skin with anomalous hair growth. Pineal teratoma are a rare variety of cerebral tumour which may arise from such an interaction between exencephalic twins, and intraspinal teratoma are commonly associated with spina bifida of varying degrees (Mitgang, 1972).

The observation by Larson, Kempers, and Titus (1969) that in their study of the literature of mono-amniotic twins they could find only a single report of such twins with differing sexes, suggests that if a breakdown of the interamniotic partition occurs in dizygous twins some form of fetus-fetus interaction is almost inevitable. 


\section{Discussion}

The present hypothesis suggests that fetus-fetus interaction occurs only when severe congenital malformations are present in both twins and does not postulate that the interaction of normal twins leads to the disappearance of the submissive twin and damage to the aggressive twin.

The value of this hypothesis may be the way it links together and explains a number of otherwise unrelated observations, and the testable predictions that follow from it. This study suggests that the incidence of intraspinal and pineal teratoma may vary in time and place with spina bifida and anencephalus, and that the scalp type hair found over or around spina bifida lesions may, in male infants, carry female chromosomes.

Since the submission of this paper, case reports of individuals with patches of anomalous skin cover, spinal teratoma, and spina bifida have come to notice (Basavarajendra, Kulkarni, and Iyengar 1973; Love, 1968).

I wish to thank Mr John Wilkin of the Department of Statistics and Operational Research, Lanchester Polytechnic, Coventry, for his statistical help: the librarian of the Warwickshire Postgraduate Medical Centre: and the many experts in this field who have, over the years, allowed me to expound this hypothesis and whose help has enabled me to state it in its present form.

Requests for reprints: Dr S. C. Rogers, General Practitioner, 4 Clifton Road, Rugby.

\section{REFERENCES}

Basavarajendra, T. B., KulKarni, A. M., and Iyengar, V. S. (1973). Spinal teratoma. J. Ass. Phycns India, 21, 529.

Carter, C. O., David, P. A., and Laurence, K. M. (1968). A family study of major central nervous system malformations in South Wales. J. med. Genet. 5, 81.

- and Evans, K. (1973). Spina bifida and anencephalus in Greater London. J. hum. Genet., 10, 209.

Hunter, W. F. and Lennox, B. (1954). The sex of teratoma. Lancet, 2, 633.

KNox, E. G. (1970). Fetus-fetus interaction-a model aetiology for anencephalus. Develop. Med. Child Neurol., 12, 167.
(1974). Twins and neural tube defects. Brit. $J$.prew soc. Med., $28,73$.

LARSON, S. L., Kempers, R. D., and Titus, J. L. (1969) Monoamniotic twins with a common umbilical cord: Amer. J. Obstet. Gynec., 105, 635.

Laurent, M., Rousseau, M. F., and Nezelof, C. (1968)o Étude caryotypique d'un teratoma sacro-coccygienoAnn. Anat. path., 13, 413.

LINDER, D. and Power, J. (1970). Further evidence fo post-meiotic origin of teratomas in the female human Ann. hum. Genet., 34, 21.

LORD, J. M. (1956). Intra-abdominal foetus in foetuo J. Path. Bact., $72,627$.

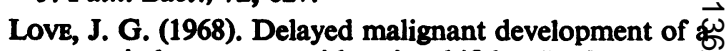
congenital teratoma with spina bifida. $J$. Neurosurg.:ल) 29, 532.

Mitoang, R. N. (1972). Teratoma occurring within myelomeningocele. J. Neurosurg., 37, 448.

MYRRS, L. M. (1959). Sex chromatin in teratomas. స్ Path. Bact., 78, 43.

Nishimura, K., Takano, K., Tanimura, T., and Yasuda M. (1958). Normal and abnormal development of human embryos: First report of the analysis of 121 缹 intact embryos. Teratology, 1, 281.

Pedlow, P. R. B. (1961). Anencephaly in a monoes amniotic twin. Brit. med. J., 2, 997.

Rickman, P. P. (1968). A new type of silver impregna silastic type $C$ catheter for use with Holter valvesip the treatment of hydrocephalus. Develop. Med. Child Neurol., Suppl., 15, 14.

Roorrs, S. C. (1969). Epidemiology of stillbirths fron congenital abnormalities in England and Wales $1961 \stackrel{2}{\rightarrow}$ 1966. Develop. Med. Child Neurol., 11, 617.

— and Weatherall, J. A. C. (1976). Anencephalus spina bifida and hydrocephalus: England and Walest 1964-72. OPCS Studies on Medical and Population Subjects, no 32. HMSO, London (in press).

Theiss, E. A., Ashry, D. J. B., and Mostofi, K. F. (1960)? Nuclear sex of testicular tumours and some related ovarian and extragonodal neaplasms. Cancer (Philad.). 13, 323.

Todorov, A. B., Cohen, K. L., SpILOtro, V., and LANDAU, E. (1974). Crainiopagus twins. J. NeuroP Neurosurg. Psychiat., 37, 1291.

Wharton, B., Edwards, J. H., and Cameron, A. H욜. (1968). Mono-amniotic twins. J. Obstet. Gynaec. Brit, Cwlth, 75, 158.

YeN, S. and MacMahon, B. (1968). Genetics of aneñ cephaly and spina bifida? Lancet, 2, 623. 